\title{
REVIEW
}

\section{Time-limited trial of intensive care treatment: an overview of current literature}

\author{
Eva E. Vink ${ }^{1,2}$, Elie Azoulay ${ }^{3}$, Arthur Caplan4, Erwin J. O. Kompanje² and Jan Bakker ${ }^{1,2,5,6,7^{*}}$
}

(c) 2018 Springer-Verlag GmbH Germany, part of Springer Nature and ESICM

\begin{abstract}
In critically ill patients, it is frequently challenging to identify who will benefit from admission to the intensive care unit and life-sustaining interventions when the chances of a meaningful outcome are unclear. In addition, the acute illness not only affects the patients but also family members or surrogates who often are overwhelmed and unable to make thoughtful decisions. In these circumstances, a time-limited trial (TLT) of intensive care treatment can be helpful. A TLT is an agreement to initiate all necessary treatments or treatments with clearly delineated limitations for a certain period of time to gain a more realistic understanding of the patient's chances of a meaningful recovery or to ascertain the patient's wishes and values. In this article, we discuss current research on different aspects of TLTs in the intensive care unit. We propose how and when to use TLTs, discuss how much time should be taken for a TLT, give an overview of the potential impact of TLTs on healthcare resources, describe ethical challenges concerning TLTs, and discuss how to evaluate a TLT.
\end{abstract}

Keywords: Intensive care, Critical care, Prognosis, Outcome, Prediction, Medical uncertainty

\section{Introduction}

Identifying patients who will benefit from ICU admission is often challenging. Where in some countries already $20 \%$ of the people die in the ICU, a trend for an increasing number of admissions, especially in the elderly, exists $[1,2]$. Medical uncertainty, involving both patient- and physician-related factors, is common on ICU admission [3]. Uncertainty can exist about the prognosis and long-term outcome, response to treatment, risk of complications, and values of the patient or their surrogates. In addition, the decision-making capacity of critically ill patients is frequently absent, and family members or surrogates are frequently unable to represent the patient because of the emotional stress and fear of losing them. A time-limited trial (TLT) of ICU can be helpful in

\footnotetext{
*Correspondence: Jan.Bakker@nyumc.org

${ }^{1}$ Department of Pulmonology and Critical Care, Langone Medical Center-Bellevue Hospital, New York University, New York, NY, USA

Full author information is available at the end of the article
}

acquiring more certainty and preventing unnecessary or disproportionate care [4]. The concept of a TLT was proposed by Vincent et al. in 2005 as 'the ICU test' [5].

In this article, we discuss current research on different aspects of TLTs in the ICU. We discuss how and when to use TLTs, how much time should be taken for a TLT, and the potential impact of TLTs on availability of healthcare and describe ethical challenges concerning TLTs and how to evaluate a TLT.

\section{Definition of a TLT}

In this article, the suggested definition of a TLT by Quill and Holloway [6] is used. They defined a TLT as: "An agreement between clinicians and a patient/family to use certain medical therapies over a defined period to see if the patient improves or deteriorates according to agreedon clinical outcomes. If the patient improves, disease directed therapy continues. If the patient deteriorates, the therapies involved in the trial are withdrawn, and goals frequently shift more purely to palliation. If significant clinical uncertainty remains, another TLT might be renegotiated." 


\section{How and when to use TLTs of ICU}

A TLT is an agreement to initiate all indicated treatments (i.e., mechanical ventilation, renal replacement therapy, vasopressor support, extracorporeal membrane oxygenation) or treatments with clearly delineated limitations (i.e., a do-not-resuscitate order) for a certain period of time to improve uncertainty about benefit. This requires enhanced communication between all persons involved in the patient's treatment as well as with the patient and their family/surrogates. The concept of a TLT is only an option when withdrawal of life support is permissible; therefore, a TLT would not be feasible in some countries (i.e., Israel and Arabic countries).

\section{Take home message}

TLTs can, when executed well, improve quality of care and provide patients with the care they desire and can benefit from

TLTs can be initiated at two points in time. First, they may be considered on admission when outcome and/or patient preferences are (still) unclear and optimal treatment for a limited period of time is likely to improve final decision making. A TLT typically applies to patients with limited quality of life associated with limited reserves. For example, a TLT is not indicated in a young victim of polytrauma or a patient with severe septic shock and

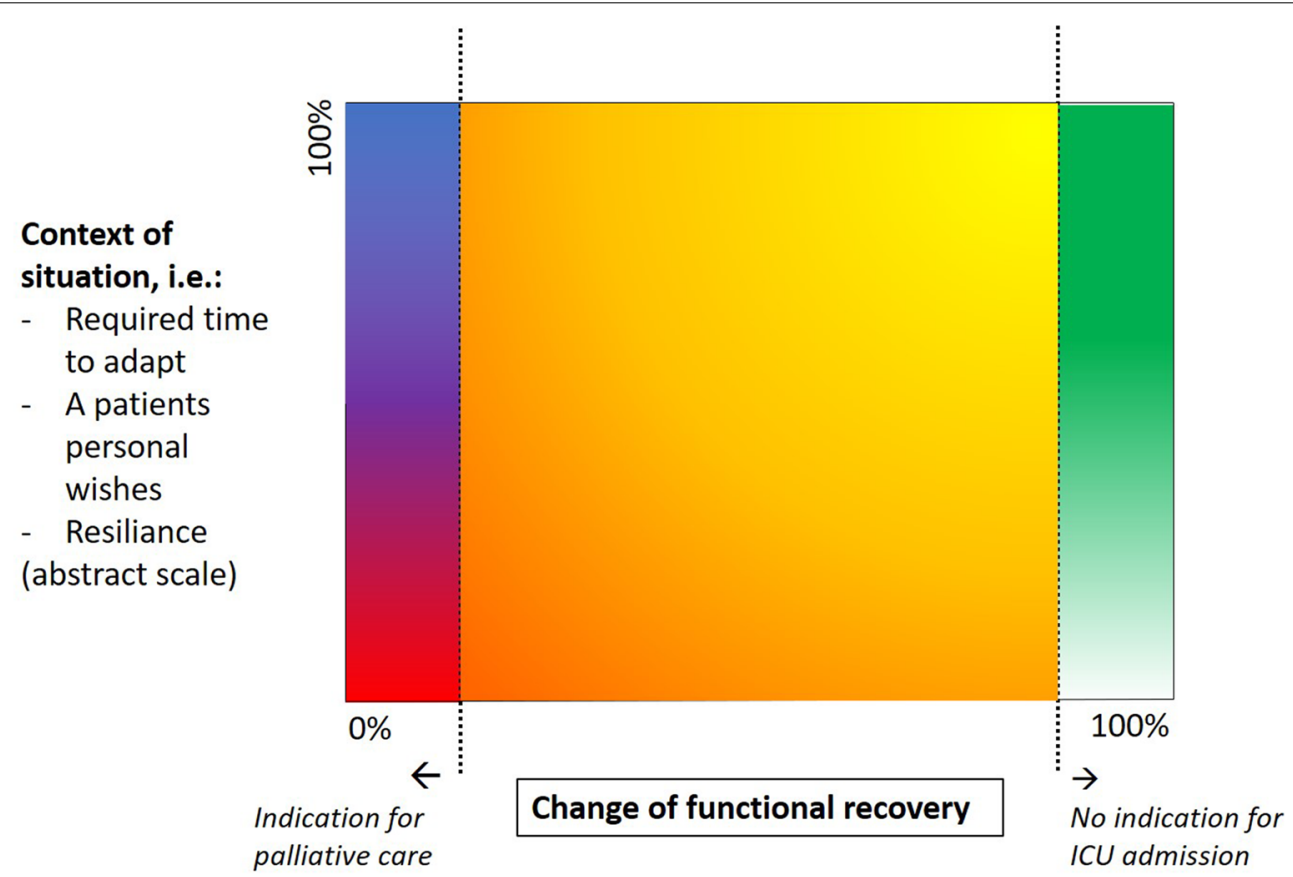

Fig. 1 Schematic view of (un)certainties in critically ill patients. Theoretically, patients admitted to the ICU can be classified based on two scales. The first scale, depicted on the X-axis of this figure, represents the change of functional survival. Patients at the right end of the spectrum are'too well'for admission. These patients would also survive without ICU care and so admission would result in excessive care. The dashed line on the right side of the X-axis marks this point. At the left end of the X-axis, patients are 'too ill'for ICU admission. These patients would die despite optimal treatment in the ICU, and so admission would be disproportionate and could even be considered harmful; palliative care would be more appropriate. The dashed line on the left side of the X-axis marks this point. The Y-axis represents an abstract scale, the context of the situation. Multiple factors are represented, i.e., patients' preferences, resilience, and the possible required time for patients and families to adapt. At the top of the Y-axis, the context is optimal: i.e., the preferences are clear, no time is needed to adapt, and no issues need to be clarified. At the origin of the Y-axis, the context is not optimal, i.e., preferences are not clear, and time to adapt or to come to an agreement is required. Both this context (Y-axis) and the change in functional survival (X-axis) influence the correct indication for ICU admission and a TLT. The green-to-white area represents patients with a high chance of functional survival in an optimal context; ICU admission is not indicated. The white area falls outside the scope of this article (high chance of survival in a non-optimal context): preferences should be explored outside the ICU (i.e., out-patient clinic). The blue-to-red area represents patients with a high chance of mortality or non-functional recovery in a non-optimal context: i.e., patients and families might need time to adapt or preferences and effect of treatments that may need to be instituted are unclear. Palliative care with special attention to communication could be preferable over a TLT. The orange-to-yellow part of the figure represents patients with a risk of death and a chance of a beneficial effect of treatment in an optimal/suboptimal context that qualifies as appropriate ICU care. The orange part represents the patients who could benefit from a TLT: patients with a high probability of dying/non-functional recovery and uncertainty about the effect of ICU treatment on that survival and/or a suboptimal/non-optimal context 
no major comorbidity. Theoretically, patients admitted to the ICU can be classified based on two scales (Fig. 1). The first scale, depicted on the $\mathrm{X}$-axis of this figure, represents the chance of functional recovery. Patients at the right end of the spectrum are 'too well' for admission. These patients would also survive without ICU care and so admission would result in excessive care. The dashed line on the right side of the $\mathrm{X}$-axis marks this point. These patients should not be admitted to the ICU, unless for logistical reasons, i.e., some post-elective surgery patients [7]. Uncertainty about excessive treatment can exist. This could be solved by admitting the patient to another level of care (medium care, post-anesthesia care unit). At the left end of the X-axis, patients are 'too sick' for ICU admission. These patients would die irrespective of ICU care and so admission would be disproportionate and could even be considered harmful. In these cases, palliative care would be more appropriate. The dashed line on the left side of the $\mathrm{X}$-axis marks this point. There are exceptions to this classification: e.g., admission of a patient with a large intracerebral hematoma can be appropriate in light of a possible brain-dead organ donation procedure where the patient has no chance of survival. The point where excessive treatment and disproportionate treatment start on the $\mathrm{X}$-axis is not fixed and influenced by hospital context and social structures. The Y-axis represents an abstract scale, the context of the situation. Multiple factors are represented here, i.e., the patients' preferences, resilience, and time for patients and families to adapt. At the top of the Y-axis, the context is optimal: i.e., the preferences are clear, no time is needed to adapt, and no issues need to be clarified. At the origin of the Y-axis, the context is not optimal: i.e., preferences are not clear, and time to adapt or to come to an agreement is required. Both this context (Y-axis) and the change of functional recovery (X-axis) influence the indication for ICU admission and a TLT. The green-to-white area represents patients with a high chance of functional recovery in an optimal context; ICU admission is not indicated. The white area falls outside the scope of this article (high chance of functional recovery in a nonoptimal context): preferences should be explored outside the ICU (i.e., out-patient clinic). The blue-to-red area represents patients with a high chance of mortality or non-functional recovery in a non-optimal context: i.e., patients and families might need time to adapt or preferences and effect of treatments that may need to be instituted are unclear. Palliative care with special attention to communication could be preferable to a TLT. The orange-to-yellow part of Fig. 1 represents patients with a risk of death and the chance of a beneficial effect of treatment in an optimal/suboptimal context, which qualifies as appropriate ICU care. The orange part represents the patients that could benefit from a TLT: patients with a high probability of dying/non-functional recovery and uncertainty about the effect of ICU treatment on that survival and/or a suboptimal/non-optimal context. The extent of this area is, however, not easily defined. An international group of experts could not agree on a survival cutoff below which patients should no longer be admitted to the ICU [8]. Moreover, the majority (52\%) of experts surveyed was not even unwilling to deny admission of patients with a $1 \%$ chance of survival [8]. In addition, some doctors have prognostic pessimism regarding ICU survival, which would lead to inappropriate denial of ICU admission. In a recent study, patients deemed to have a less than $10 \%$ change of survival actually had a $40 \%$ survival rate [9]. Although patients deemed too ill' to survive ICU admission are frequently denied ICU admission, their actual survival rate was $20 \%$ [10] in adult patients and $13 \%$ in patients older than 85 years [11]. In these patients a TLT could be helpful, and $94 \%$ of experts agreed that a TLT would give these patients the optimal chance of benefit [8].

Second, besides initiating a TLT at the moment of ICU admission, a TLT may be used during an ICU stay when unexpected complications occur or an untoward clinical course evolves resulting in increased uncertainty about the final outcome. In both these cases, a TLT could benefit the patient, relatives, and treatment team in situations where the patient and his or her relatives do not agree on treatment choices with each other or with the treatment team. A TLT is primarily used to give a patient the optimal chance for benefit. Moreover, it can potentially improve patient-centered decision making and prevent disproportionate care [4]. A TLT can thus also be initiated for surrogate/family/patient-centered reasons. Many surrogates and patients feel overwhelmed when faced with decisions about complex treatments and decisions to withhold or withdraw life support [12]. Some surrogates simply need time to process options and determine the most benevolent course in keeping with their loved one's values [12]. In case of uncertain prognosis on admission, surrogates may feel that clinicians are not willing to initiate all necessary treatments because of doubt, prejudice, or cost. In addition, families or surrogates may be overly optimistic about ICU care and prognosis [13]. This often results in disconnected communication and occasional mistrust, which may end up in surrogates insisting on continuing treatment despite the medical team's advice to focus on comfort measures. TLTs can reassure surrogates that every available and warranted option is utilized. Moreover, TLTs give surrogates the opportunity to get better informed and provide family members time to adjust emotionally. In addition, TLTs can prepare surrogates and clinicians for 
Table 1 Problems associated with TLTs that last too long or are too short

\begin{tabular}{|c|c|c|}
\hline & Too long & Too short \\
\hline Patient/surrogates/family & $\begin{array}{l}\text { The impact of a too long TLT depends: } \\
\text { It could be a huge emotional burden especially if they } \\
\text { wanted to stop treatment earlier but the team wanted } \\
\text { to go on } \\
\text { If the family wants survival whatsoever then there is no } \\
\text { too long }\end{array}$ & $\begin{array}{l}\text { Inadequate assessment of potential benefit, thus leading } \\
\text { to inappropriate limitation of care } \\
\text { Emotional burden of being rushed } \\
\text { Regret/deceit feelings afterwards, negative effect on } \\
\text { mourning process } \\
\text { Losing trust in doctors/system }\end{array}$ \\
\hline Nurses/doctors & $\begin{array}{l}\text { Potential loss of compassion (compassion fatigue) } \\
\text { Emotional burden } \\
\text { Burn-out contributor } \\
\text { Decreased quality of care }\end{array}$ & $\begin{array}{l}\text { Rushed to a definite decision } \\
\text { May impose precedent for future patients if not recog- } \\
\text { nized } \\
\text { Providing inadequate care } \\
\text { Emotional burden when recognized } \\
\text { Burn-out potential }\end{array}$ \\
\hline Hospital directors/organization & $\begin{array}{l}\text { When family perceives as too long it will result in the loss } \\
\text { of confidence in the organization } \\
\text { Increased costs for DRG-like systems }\end{array}$ & $\begin{array}{l}\text { When recognized by family/surrogates they might lose } \\
\text { trust in the organization as a whole } \\
\text { On the other hand, a decrease in costs and maximal gain } \\
\text { in profit (short duration and full refund in DRG-like } \\
\text { systems) }\end{array}$ \\
\hline
\end{tabular}

DRG diagnosis-related group

discussions on a possible shift toward comfort-care strategies when the desired outcome seems unreachable [14].

Clear and concise communication is very important for a successful TLT where proactive communication with family members of critically ill patients, including family members' presence during rounds and subsequent family conferences, may lessen the burden of bereavement [15]. Some have proposed a five-step framework for initiating TLTs: the clinical problem and prognosis have to be defined, patient goals and priorities clarified, objective markers of improvement or deterioration determined, a time frame for reevaluation suggested, and finally potential actions at the end of a TLT defined [6]. A recent study, however, showed that TLTs are infrequently offered in conferences with surrogates of patients with a high risk of dying. When they are offered, they are incompletely discussed: clinicians frequently do not inform surrogates about how to value a TLT or its rationale and variable scenarios on how to move forward [16].

\section{How much time is needed for a TLT?}

Although time is an essential element of the TLT, only few studies have actually addressed this. In a recent editorial comment, Quill and Holloway made suggestions on the duration of a TLT in critically ill patients [6]. In patients requiring mechanical ventilation, the optimal duration of the TLT increased from 3 days (patients with hypoxic ischemic encephalopathy) to 3-7 days in patients with end-stage congestive heart failure and 7-14 days for patients with severe stroke. As these recommendations were not based on studies, they urged using considerable discretion as severity of illness, comorbidities, preferences, and time needed to assess effects were important elements in defining the optimal duration. Lecuyer et al. investigated the effect of a 5-day full-code TLT in 188 patients with hematologic malignancies or solid tumors requiring mechanical ventilation and having at least one additional organ failure [17]. Forty-five percent $(n=85)$ of these patients died during the TLT. Of the patients that survived the TLT, an increasing number of failing organs 1 day after the TLT was linearly related to mortality. Only $5 \%$ of the patients with six failing organs survived to hospital discharge. All patients requiring initiation of mechanical ventilation, vasopressors, or dialysis more than 3 days following admission died [17]. This study suggests that increases in severity of disease within the first 3-5 days of a TLT could serve as a reliable endpoint for the TLT. Using a stage-transition model of 920 cancer patients with poor-prognosis solid tumors or hematologic neoplasms validated in 624 patients, Shrime et al. [18] modeled the effect of using a 3-, 8-, or 15-day TLT versus unlimited ICU care on 30-day survival stratified by the sequential organ failure assessment (SOFA) score. They found that cancer patients with lower severity of illness benefited most from a longer duration of a TLT (up to 15 days). Although a 3-day TLT always resulted in lower survival duration, the incremental survival durations were very small (up to 3 days). For patients with solid tumors, a 1-4-day TLT resulted in equivalent survival duration compared with unlimited ICU treatment [18]. From these studies, it can be concluded that the duration of a TLT should take into account the pre-existing conditions of the patient and the average time needed to show a response, or the lack thereof, to a treatment. Therefore, at least $24-72 \mathrm{~h}$ should be reserved for a TLT. 
Finding the optimal duration for a TLT is challenging. Both TLTs that are too short and too long are associated with problems (Table 1). When at the end of a TLT uncertainty remains, another TLT can be renegotiated [6]. Ethical challenges associated with another TLT are discussed below.

\section{Potential impact of TLTs on availability of healthcare}

ICU costs continue to rise because of the increasing number of beds, days spent at the ICU, bed occupancy, and costs per day [19]. Admission to the ICU with the prospect of ultimate non-survival is deemed inappropriate care in most cases (except organ donation procedures, providing time for the family to arrive in the hospital, delivery of the unborn baby in a brain-dead patient, etc.) [4]. In addition, using resources to deliver inappropriate care should thus be limited. In general, patients do not prefer ICU admission when the likelihood is only to delay the inevitable death during that hospital admission. Therefore, advanced care planning could reduce inappropriate ICU care. In a systematic review, Khandelwal et al. [20] showed that advance care planning and palliative care interventions resulted in a reduction in ICU admissions and ICU length of stay before death. Lilly et al. showed that the introduction of proactive communication with patients and families resulted in a sustained increase in overall ICU survival [21, 22]. The majority of this improvement could be related to the improved survival of seriously ill patients who only improved slowly, whereas also more less sick patients where admitted. Although Daly et al. [23] failed to show a significant effect of improved communication strategies, they were only able to involve $75 \%$ of the patients/families, whereas Lilly et al. [21] were able to vertically include all patients/families (99\%). A TLT could also serve to limit inappropriate care by allowing patients who are unlikely to achieve their goals to gain insight into their prognosis [24]. Therefore, when conducted carefully, TLTs could also reduce the length of ICU stay $[21,22,25]$. A TLT should be a package where communication with the patient/family has a key role, and timely end-of-life discussions and involvement of palliative care together can help reduce inappropriate care and improve optimal delivery of care to a larger group of patients. Since communication is the cornerstone of not only a successful TLT but also of successful ICU treatment, research should focus on decision-making models used by ICU clinicians and families.

\section{Ethical challenges concerning TLTs}

Treatment of critically ill patients with an uncertain prognosis often balances between life-prolonging measures and their possible complications versus non-beneficial interventions and changing to comfort care too early (Table 1 ). When at the end of a TLT uncertainty remains, another TLT can be renegotiated [6]; although this provides more time, the evaluation of the balance between disproportionate and beneficial care remains. This becomes especially problematic when the goal of the patient or his surrogates is merely: "not to be dead" [26]. A TLT in this context may give the patient/surrogate time to better evaluate the patient's condition so that goals may change. Especially in cancer patients, who initially may just focus on survival and more so than patients without cancer [27], families may change their perspective when faced with a poor prognosis [28-30]. For surrogates, especially when the patient is unable to communicate, a TLT is especially challenging [14, 31]. Although the consequences of a conflict based on these aspects may vary between different countries and states the question may arise: 'Who is in control?': the medical team or family/surrogate. A recent statement of multiple European and American ICU societies recommended first using intensive communication to resolve a conflict about potentially inappropriate treatments followed by a fair process of conflict resolution that could contain a second medical opinion and review by an interdisciplinary hospital ethics committee [31]. Where the consensus statement stated that clinicians should not provide futile interventions, the definition of these interventions was far more restrictive than frequently used in clinical practice [31]. Although $90 \%$ of families/surrogates desire recommendations from the intensivist, only $50 \%$ of intensivists actually provide them with wide variation between practices [32-34].

When the outcome of a TLT is that recovery is no longer feasible, this can be perceived as a form of patient abandonment by both surrogates and staff, and withdrawal of life support can be perceived as a non-beneficent act. In family meetings and discussions, it should be emphasized that abandonment never occurs, but that at this stage, emphasis is placed on comfort and palliation. Care for patients after withdrawal of life support at the end of a TLT therefore requires specific skills to allow a patient to die in comfort, meeting his end-of-life goals [35] while at the same time gaining the trust of both surrogates and staff.

\section{How to evaluate a TLT}

At the end of a TLT, there are three possible outcomes. First, the patient has improved and moved into the green or yellow area in Fig. 1. Second, the situation of the patient has not changed significantly since the start of the TLT. If this is related to unknown preferences of the patient or a still ongoing dispute with the family/surrogates, ongoing communication and additional psychologic support should be provided [35]. When, however, the lack of 


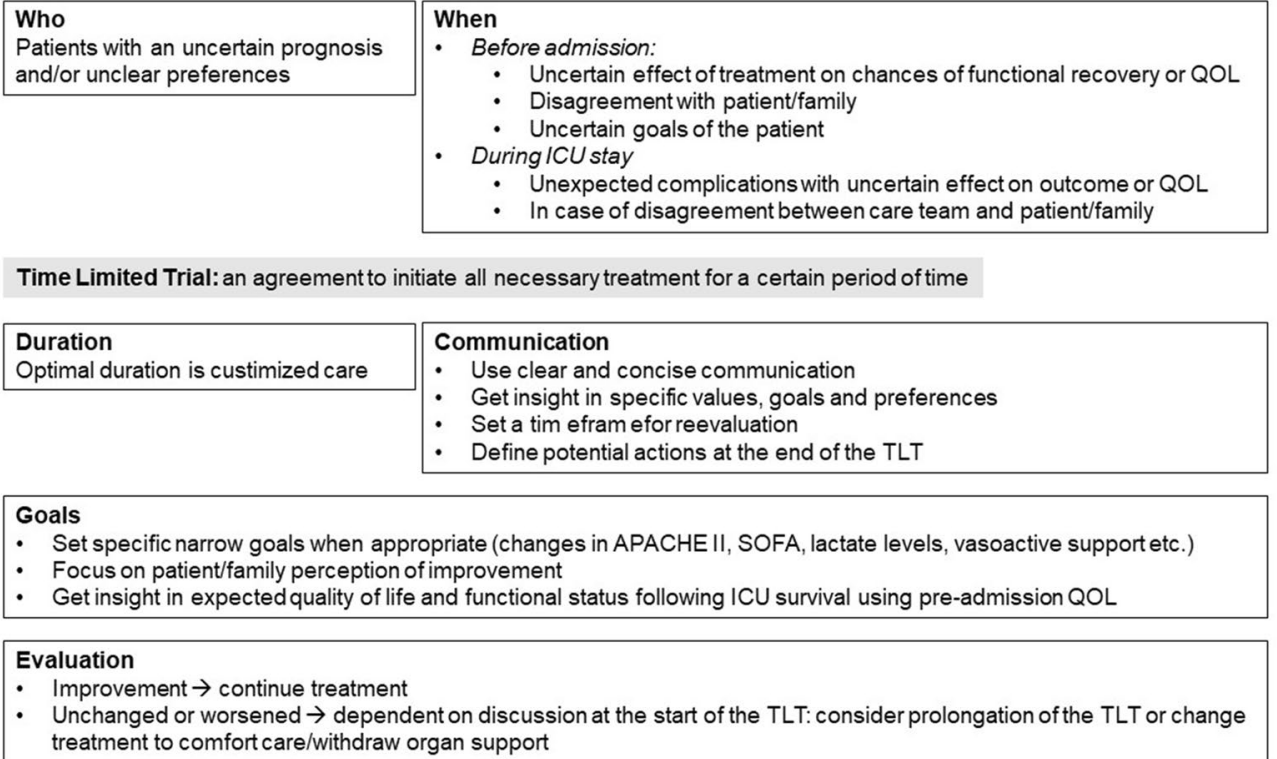

Fig. 2 A proposal of the clinical and practical use of a TLT. QOL quality of life

progress is related to the absence of improvement in the overall clinical condition of the patient, this should be considered similar to the third option where the patient's condition actually worsened during the TLT. Studies on lactate show that no improvement in the clinical condition implies a worse outcome [36]. This scenario should thus be explained and discussed at the start of the TLT where clear concrete and measurable goals should be set when discussing the evaluation of the TLT [14]. Bruce et al. [14] defined narrow and broad goals for a TLT. Narrow goals, more frequently used in surgical/anesthesia ICUs, would be focused on for example trends in laboratory values or weaning efforts, organ failure scores, dependence on circulatory support, etc. Changes in APACHE II scores [37] and Sequential Organ Failure Scores [38, 39], as well as lactate levels [40, 41] and level of vasoactive support [42], may provide important information in these conditions. Broad goals, more frequently used in medical/neuro ICU's, would focus more on aspects related to quality of life like wakefulness, mobility, responsiveness, and independence. The difference in focus (broad versus narrow goals) is unit (surgical vs. nonsurgical) specific, but also specialty (internal vs. surgical/anesthesia specialists) dependent.

Surrogates are often too optimistic regarding expectations compared with physicians. Cox et al. [13] showed that where clinicians expected a chance of survival of $44 \%$ in specific critically ill patients, surrogates expected a 93\% chance of survival. Although physicians are more accurate in predicting outcome and surrogates perform better than chance alone, surrogates frequently disagree based on religious beliefs and hope [43]. Next to the patient, family/ surrogates have an important role in these evaluations as ultimately when survival is likely, the likelihood of attaining an acceptable quality of life or functional status is important [28]. Relatives in close contact with the patient can adequately reflect the patient's functional status on admission to the ICU [44] where a poor health-related quality of life before admission is already an important predictor of survival [45]. However, ultimately the patient is the only person who can truly value the gap between their actual and anticipated quality of life [46].

\section{Palliative care}

Whenever doubt about the appropriateness of ICU admission is in question, involving palliative care might be considered. Palliative care should surely be involved as soon as a TLT is started. Relief of symptoms is a key component of critical care for all ICU patients, regardless of condition or prognosis. When the outcome of a TLT is however negative, relief of symptoms should be the only focus of treatment, with special attention to treatment of distress, agitation, delirium, dyspnea, pain, and thirst, which is described in more detail in other articles [47-50]. Life-prolonging treatments without effect on distress, i.e., mechanical ventilation, renal replacement therapy, vasopressor support, and extracorporeal membrane oxygenation, should be ceased, and a do-not-resuscitate order should be in place. Also during this phase of treatment communication with patients and family/surrogates is of utmost importance. 
Table 2 Core elements of a time-limited trial

\begin{tabular}{|c|c|}
\hline Element & Comment \\
\hline Advanced care planning & $\begin{array}{l}\text { The presence of advanced care directives would make it much easier to design a TLT and address more } \\
\text { precisely the personal preferences of the patient }\end{array}$ \\
\hline Multidisciplinary team & $\begin{array}{l}\text { A TLT should be a team effort that involves all parties participating in the care of the patient (intensivists, } \\
\text { nurses, referring specialists, palliative care, religious/spiritual support persons if applicable, etc.) }\end{array}$ \\
\hline Palliative care & $\begin{array}{l}\text { A palliative care team could be involved early in patient care when pre-existing problems of frailty, qual- } \\
\text { ity of life,and pre-admission permanent organ disfunction are present. Ideally, the palliative care team } \\
\text { should already be involved before ICU admission (if possible) }\end{array}$ \\
\hline Ethics committee and legal department & $\begin{array}{l}\text { In some cases, involvement of the Ethics Committee to review the case on its ethical merits or the legal } \\
\text { department to review possible legal aspects of the case might be relevant. Ideally, these consultations } \\
\text { should take place before discussing a TLT with the patient and/or relatives }\end{array}$ \\
\hline Communication & $\begin{array}{l}\text { Clear and concise communication is important for a successful TLT. Proactive communication with family } \\
\text { members of critically ill patients, including family members' presence during rounds and subsequent } \\
\text { family conferences are preferred }\end{array}$ \\
\hline
\end{tabular}

Table 3 Problem solving in the process of a TLT

What do you say to families on a daily basis?

How long should a TLT be?

\section{Table 4 Pitfalls of a TLT}

Starting a TLT when the goal should actually be palliative care

In this case, initiating a TLT would result in non-beneficial interventions and disproportionate care. Potentially, patients, families, and surrogates can get false hope for recovery. A TLT would only postpone the inevitable death

Not immediately starting a TLT when indicated

When a TLT is not immediately initiated when indicated, a barrier to start a TLT can be experienced

Lack of communication during a TLT

Communication and evaluation are of utmost importance for a successful TLT. Without special attention to communication to explore preferences and update on the situation, a TLT cannot be successful. Especially in case of a conflict, even more attention should be paid to communication

Incorrect duration of a TLT

A too short duration of a TLT will not provide optimal chances for survival. On the other hand, a too long duration when palliative care should be initiated will result in improved survival but non-beneficial interventions and disproportionate care

Failure to keep the family/surrogates updated or informed

When families/surrogates are not aware of the current situation, the discussion of the outcome at the end of a TLT can potentially surprise the patient/ family and could potentially result in a conflict and inability to proceed to palliative care

\section{How to implement a TLT}

Based on the topics discussed in this overview, a proposal of the clinical and practical use of a TLT is given in Fig. 2. Table 2 shows the core elements of a TLT, Table 3 shows some of the most frequently asked questions on TLTs, and Table 4 shows the most important pitfalls of a TLT. 


\section{Conclusion}

A TLT is an agreement among the patient, surrogates and treating clinicians to initiate certain life-sustaining treatments for a certain period of time to better assess patients' response to ICU care and the possibilities of a meaningful outcome. TLTs can give better insight into prognosis when outcome is difficult to assess on admission or when unexpected complications occur during admission, resulting in doubt about their impact on the final outcome. Communication, clearly defined measurable goals, and evaluation are of utmost importance for a successful TLT. TLTs can, when executed well, improve quality of care and quality of dying when intensive care can no longer provide a meaningful outcome.

\begin{abstract}
Author details
${ }^{1}$ Department of Pulmonology and Critical Care, Langone Medical Center-Bellevue Hospital, New York University, New York, NY, USA. ${ }^{2}$ Department of Intensive Care Adults, Erasmus MC-University Medical Center Rotterdam, Rotterdam, The Netherlands. ${ }^{3}$ Service de Reanimation Medicale, Hopital Saint-Louis et Universite Paris 7, Assistance Publique, Hospitaux de Paris, Paris, France. ${ }^{4}$ Division of Medical Ethics, School of Medicine, New York University, New York, NY, USA. ${ }^{5}$ Division of Pulmonary, Allergy and Critical Care, University Medical Center, Columbia University College of Physicians and Surgeons, New York, NY, USA ${ }^{6}$ Departamento de Medicina Intensiva, Facultad de Medicina, Pontificia Universidad Católica de Chile, Santiago, Chile. ${ }^{7}$ Department of Pulmonary and Critical Care, New York University, 462 First avenue, New York, NY 10016, USA.
\end{abstract}

\section{Compliance with ethical standards}

\section{Conflicts of interest}

The authors declare that they have no conflict of interest.

Received: 17 February 2018 Accepted: 23 July 2018

Published online: 22 August 2018

\section{References}

1. Angus DC, Barnato AE, Linde-Zwirble WT, Weissfeld LA, Watson RS, Rickert T, Rubenfeld GD (2004) Use of intensive care at the end of life in the United States: an epidemiologic study. Crit Care Med 32:638-643

2. Teno JM, Gozalo PL, Bynum JP, Leland NE, Miller SC, Morden NE, Scupp T, Goodman DC, Mor V (2013) Change in end-of-life care for Medicare beneficiaries: site of death, place of care, and health care transitions in 2000, 2005, and 2009. JAMA 309:470-477

3. Ghosh AK (2004) Understanding medical uncertainty: a primer for physicians. J Assoc Phys India 52:739-742

4. Kompanje EJ, Piers RD, Benoit DD (2013) Causes and consequences of disproportionate care in intensive care medicine. Curr Opin Crit Care 19:630-635

5. Vincent $J \mathrm{~L}$ (2005) Withdrawing may be preferable to withholding. Crit Care 9:226-229

6. Quill TE, Holloway R (2011) Time-limited trials near the end of life. JAMA 306:1483-1484

7. Kahan BC, Koulenti D, Arvaniti K, Beavis V, Campbell D, Chan M, Moreno R, Pearse RM, International Surgical Outcomes Study (2017) Critical care admission following elective surgery was not associated with survival benefit: prospective analysis of data from 27 countries. Intensive Care Med 43:971-979

8. Sprung CL, Danis M, lapichino G, Artigas A, Kesecioglu J, Moreno R, Lippert A, Curtis JR, Meale P, Cohen SL, Levy MM, Truog RD (2013) Triage of intensive care patients: identifying agreement and controversy. Intensive Care Med 39:1916-1924
9. Wildman MJ, Sanderson C, Groves J, Reeves BC, Ayres J, Harrison D, Young D, Rowan K (2007) Implications of prognostic pessimism in patients with chronic obstructive pulmonary disease (COPD) or asthma admitted to intensive care in the UK within the COPD and asthma outcome study (CAOS): multicentre observational cohort study. BMJ 335:1132

10. lapichino G, Corbella D, Minelli C, Mills GH, Artigas A, Edbooke DL, Pezzi A Kesecioglu J, Patroniti N, Baras M, Sprung CL (2010) Reasons for refusal of admission to intensive care and impact on mortality. Intensive Care Med 36:1772-1779

11. Sprung CL, Artigas A, Kesecioglu J, Pezzi A, Wiis J, Pirracchio R, Baras M, Edbrooke DL, Pesenti A, Bakker J, Hargreaves C, Gurman G, Cohen SL, Lippert A, Payen D, Corbella D, lapichino G (2012) The Eldicus prospective, observational study of triage decision making in European intensive care units. Part II: intensive care benefit for the elderly. Crit Care Med 40:132-138

12. Schenker Y, Crowley-Matoka M, Dohan D, Tiver GA, Arnold RM, White DB (2012) I don't want to be the one saying 'we should just let him die': intrapersonal tensions experienced by surrogate decision makers in the ICU. J Gen Intern Med 27:1657-1665

13. Cox CE, Martinu T, Sathy SJ, Clay AS, Chia J, Gray AL, Olsen MK, Govert JA, Carson SS, Tulsky JA (2009) Expectations and outcomes of prolonged mechanical ventilation. Crit Care Med 37:2888-2894

14. Bruce CR, Liang C, Blumenthal-Barby JS, Zimmerman J, Downey A, Pham L, Theriot L, Delgado ED, White D (2015) Barriers and facilitators to initiating and completing time-limited trials in critical care. Crit Care Med 43:2535-2543

15. Lautrette A, Darmon M, Megarbane B, Joly LM, Chevret S, Adrie C, Barnoud D, Bleichner G, Bruel C, Choukroun G, Curtis JR, Fieux F, Galliot R, Garrouste-Org Georges H, Goldgran-Toledano D, Jourdain M, Loubert G, Reignier J, Saidi F, Souweine B, Vincent F, Barnes NK, Pochard F, Schlemmer B, Azoulay E (2007) A communication strategy and brochure for relatives of patients dying in the ICU. N Engl J Med 356:469-478

16. Schenker Y, Tiver GA, Hong SY, White DB (2013) Discussion of treatment trials in intensive care. J Crit Care 28:862-869

17. Lecuyer L, Chevret S, Thiery G, Darmon M, Schlemmer B, Azoulay E (2007) The ICU trial: a new admission policy for cancer patients requiring mechanical ventilation. Crit Care Med 35:808-814

18. Shrime MG, Ferket BS, Scott DJ, Lee J, Barragan-Bradford D, Pollard T, Arabi YM, Al-Dorzi HM, Baron RM, Hunink MG, Celi LA, Lai PS (2016) Time-limited trials of intensive care for critically ill patients with cancer: how long is long enough? JAMA Oncol 2:76-83

19. Halpern NA, Pastores SM (2010) Critical care medicine in the United States 2000-2005: an analysis of bed numbers, occupancy rates, payer mix, and costs. Crit Care Med 38:65-71

20. Khandelwal N, Curtis JR (2014) Economic implications of end-of-life care in the ICU. Curr Opin Crit Care 20:656-661

21. Lilly CM, De Meo DL, Sonna LA, Haley KJ, Massaro AF, Wallace RF, Cody S (2000) An intensive communication intervention for the critically ill. Am J Med 109:469-475

22. Lilly CM, Sonna LA, Haley KJ, Massaro AF (2003) Intensive communication: four-year follow-up from a clinical practice study. Crit Care Med 31:S394-\$399

23. Daly BJ, Douglas SL, O'Toole E, Gordon NH, Hejal R, Peerless J, Rowbottom J, Garland A, Lilly C, Wiencek C, Hickman R (2010) Effectiveness trial of an intensive communication structure for families of long-stay ICU patients. Chest 138:1340-1348

24. Curtis JR, Engelberg RA, Bensink ME, Ramsey SD (2012) End-of-life care in the intensive care unit: can we simultaneously increase quality and reduce costs? Am J Respir Crit Care Med 186:587-592

25. Barnato AE, Tate JA, Rodriguez KL, Zickmund SL, Arnold RM (2012) Norms of decision making in the ICU: a case study of two academic medical centers at the extremes of end-of-life treatment intensity. Intensive Care Med 38:1886-1896

26. Finucane TE (1999) How gravely ill becomes dying: a key to end-of-life care. JAMA 282:1670-1672

27. Slevin ML, Stubbs L, Plant HJ, Wilson P, Gregory WM, Armes PJ, Downer SM (1990) Attitudes to chemotherapy: comparing views of patients with cancer with those of doctors, nurses, and general public. BMJ 300:1458-1460

28. Fried TR, Bradley EH, Towle VR, Allore H (2002) Understanding the treatment preferences of seriously ill patients. N Engl J Med 346:1061-1066 
29. Heyland DK, Dodek P, Rocker G, Groll D, Gafni A, Pichora D, Shortt S, Tranmer J, Lazar N, Kutsogiannis J, Lam M (2006) What matters most in end-of-life care: perceptions of seriously ill patients and their family members. CMAJ 174:627-633

30. Lloyd CB, Nietert PJ, Silvestri GA (2004) Intensive care decision making in the seriously ill and elderly. Crit Care Med 32:649-654

31. Bosslet GT, Pope TM, Rubenfeld GD, Lo B, Truog RD, Rushton CH, Curtis $J R$, Ford DW, Osborne M, Misak C, Au DH, Azoulay E, Brody B, Fahy BG, Hall JB, Kesecioglu J, Kon AA, Lindell KO, White DB (2015) An Official ATS/ AACN/ACCP/ESICM/SCCM Policy Statement: responding to requests for potentially inappropriate treatments in intensive care units. Am J Respir Crit Care Med 191:1318-1330

32. White DB, Malvar G, Karr J, Lo B, Curtis JR (2010) Expanding the paradigm of the physician's role in surrogate decision-making: an empirically derived framework. Crit Care Med 38:743-750

33. Johnson SK, Bautista CA, Hong SY, Weissfeld L, White DB (2011) An empirical study of surrogates' preferred level of control over value-laden life support decisions in intensive care units. Am J Respir Crit Care Med 183:915-921

34. Brush DR, Rasinski KA, Hall JB, Alexander GC (2012) Recommendations to limit life support: a national survey of critical care physicians. Am J Respir Crit Care Med 186:633-639

35. Cook D, Rocker G (2014) Dying with dignity in the intensive care unit. $N$ Engl J Med 370:2506-2514

36. Kliegel A, Losert H, Sterz F, Holzer M, Zeiner A, Havel C, Laggner AN (2004) Serial lactate determinations for prediction of outcome after cardiac arrest. Medicine (Baltimore) 83:274-279

37. Chang RW, Jacobs S, Lee B (1988) Predicting outcome among intensive care unit patients using computerised trend analysis of daily Apache II scores corrected for organ system failure. Intensive Care Med 14:558-566

38. Ferreira FL, Bota DP, Bross A, Melot C, Vincent JL (2001) Serial evaluation of the SOFA score to predict outcome in critically ill patients. JAMA 286:1754-1758

39. Peres Bota D, Melot C, Lopes Ferreira F, Nguyen Ba V, Vincent JL (2002) The Multiple Organ Dysfunction Score (MODS) versus the Sequential Organ Failure Assessment (SOFA) score in outcome prediction. Intensive Care Med 28:1619-1624

40. Bakker J, Gris P, Coffernils M, Kahn R, Vincent J (1996) Serial blood lactate levels can predict the development of multiple organ failure following septic shock. Am J Surg 171:221-226

41. Vincent JL, Quintairos ESA, Couto L Jr, Taccone FS (2016) The value of blood lactate kinetics in critically ill patients: a systematic review. Crit Care 20:257
42. Abid O, Akca S, Haji M, Vincent JL (2000) Strong vasopressor support may be futile in the intensive care unit patient with multiple organ failure. Crit Care Med 28:947-949

43. White DB, Ernecoff N, Buddadhumaruk P, Hong S, Weissfeld L, Curtis JR, Luce JM, Lo B (2016) Prevalence of and factors related to discordance about prognosis between physicians and surrogate decision makers of critically ill patients. JAMA 315:2086-2094

44. Hofhuis JG, Dijkgraaf MG, Hovingh A, Braam RL, van de Braak L, Spronk PE, Rommes JH (2011) The Academic Medical Center Linear Disability Score for evaluation of physical reserve on admission to the ICU: can we query the relatives? Crit Care 15:R212

45. Hofhuis JG, Spronk PE, van Stel HF, Schrijvers AJ, Bakker J (2007) Quality of life before intensive care unit admission is a predictor of survival. Crit Care 11:R78

46. Calman KC (1984) Quality of life in cancer patients-an hypothesis. J Med Ethics 10:124-127

47. Puntillo K, Nelson JE, Weissman D, Curtis R, Weiss S, Frontera J, Gabriel M, Hays R, Lustbader D, Mosenthal A, Mulkerin C, Ray D, Bassett R, Boss R, Brasel K, Campbell M (2014) Palliative care in the ICU: relief of pain, dyspnea, and thirst-a report from the IPAL-ICU Advisory Board. Intensive Care Med 40:235-248

48. Barr J, Fraser GL, Puntillo K, Ely EW, Gelinas C, Dasta JF, Davidson JE, Devlin JW, Kress JP, Joffe AM, Coursin DB, Herr DL, Tung A, Robinson BR, Fontaine DK, Ramsay MA, Riker RR, Sessler CN, Pun B, Skrobik Y, Jaeschke R (2013) Clinical practice guidelines for the management of pain, agitation, and delirium in adult patients in the intensive care unit. Crit Care Med 41:263-306

49. Mahler DA, Selecky PA, Harrod CG, Benditt JO, Carrieri-Kohlman V, Curtis JR, Manning HL, Mularski RA, Varkey B, Campbell M, Carter ER, Chiong JR, Ely EW, Hansen-Flaschen J, O'Donnell DE, Waller A (2010) American College of Chest Physicians consensus statement on the management of dyspnea in patients with advanced lung or heart disease. Chest 137:674-691

50. Parshall MB, Schwartzstein RM, Adams L, Banzett RB, Manning HL, Bourbeau J, Calverley PM, Gift AG, Harver A, Lareau SC, Mahler DA, Meek PM, O'Donnell DE (2012) An official American Thoracic Society statement: update on the mechanisms, assessment, and management of dyspnea. Am J Respir Crit Care Med 185:435-452 